Article

\title{
The 'Analogue City’: Mapping and Acting in Antwerp’s Digital Geographies
}

\author{
Chiara Cavalieri ${ }^{1, *}$, Michaël Stas ${ }^{2}$ and Marcelo Rovira Torres ${ }^{3}$ \\ 1 LOCI-SST, UCLouvain, 1348 Louvain-la-Neuve, Belgium; E-Mail: chiara.cavalieri@uclouvain.be \\ 2 Department of Urbanism and Landscape, Oslo School of Architecture and Design, 0175 Oslo, Norway; \\ E-Mail: michael.stas@aho.no \\ 3 Independent Researcher, Sweden; E-Mail: marcelo.rovira@icloud.com \\ * Corresponding author
}

Submitted: 1 July 2020 | Accepted: 3 September 2020 | Published: 15 December 2020

\begin{abstract}
This article discusses digital geographies by tracing, mapping, and revealing a series of spaces bounded by a multiplex digital infrastructure. By proposing 'descriptivism' as a complementary approach to digital mapping, this work discloses the city of Antwerp as the intertwining of visible and invisible networks. The 'Analogue City' is the title of both a design workshop and of a collective act of mapping that progressively reveals the city of Antwerp as a set of different spaces of information flows. By engaging the notion of mapping as object and practice, this work describes the production of a multiscale and multi-space representation, as a process of collective and performative cartography. Through the combination of different scales, spaces, and mapping techniques, the city of Antwerp is unfolded as the result of security, mobility, and social networks. As a mapping operation, the 'Analogue City' is a threefold object: (a) an interactive, intentionally large map; (b) a series of mapping interventions throughout the city; and ultimately (c) a temporary exhibition.
\end{abstract}

\section{Keywords}

Analogue City; Antwerp; description; digital skin; mapping; performative cartographies

\section{Issue}

This article is part of the issue "Digital Geographies and the City" edited by Wen Lin (Newcastle University, UK).

(C) 2020 by the authors; licensee Cogitatio (Lisbon, Portugal). This article is licensed under a Creative Commons Attribution 4.0 International License (CC BY).

\section{Between Digital and Analogue Geographies}

Nowadays, digital transition is imposing a radical shift in the way architects, urbanists, and designers conceive, produce, and use maps. At the same time, cities are at the threshold of both a centralised and technocratic control which increasingly relies on digital information and 'big' data accumulation: Every two days more data is being produced in the world than in all of history prior to 2003 (Kitchin, 2014). As a consequence, while over the last decades cities and territories have been radically changing, their representation is becoming more and more controversial. Paradoxically, despite the large availability of data and new technologies, digital images are overwhelming the complexity of spaces while detaching the representation from the space of cities itself. This article observes 'digital geographies' as physical spaces produced by the digital infrastructure
(Ash, Kitchin, \& Leszczynski, 2018), starting by surveying those physical devices that act as bridges between urban and virtual space (Kinsley, 2014) and ultimately mapping a set of geographies that, while being invisible (Merx, 2017), contribute to the (re)production of urban physical spaces. This investigation has been realised through the production of an exploratory cartography during a five days interdisciplinary workshop (February 11th-15th, 2019). The workshop was part of the third edition of the 'International Design Week' held at the University of Antwerp, Belgium, whose proposed overall theme was that of 'liminality': that condition in-between, that space in transition, the time between the 'preceding' and the 'next' (University of Antwerp, 2018). Within this framework and together with the students, we proposed to explore the notion of liminality between virtual and physical space, by documenting the points where the digital infrastructure becomes tangible and visible. 
The exploration was implemented via a collective act of what we could define 'performative' cartography, where the notion of 'performance' assumes a twofold meaning. On the one hand, it refers to the cartographical turning point that saw the emergence of collaborativeperformative cartographies as a counter tendency in geographical studies (Lin, 2013; Verhoeff, 2012), where bottom-up and demonstrative mapping practices were strongly opposed to the traditional top-down desktop operations. On the other hand, we make use of the notion of 'performative' for engaging mapping as a practice rather than as an object, namely as a cultural practice in the process of its making, as an existence rather than an essence (Cosgrove, 2008; Crampton, 2009).

Within this framework, we proposed the students to distinguish between digital and physical (which we defined as 'analogue') space, and to co-produce a handmade map of the 'digital' infrastructure of the city of Antwerp. More in particular, we stressed the 'object' map as a way for connecting it with some mapping 'practices' that we executed in space. The main output is that of a large $(3,3 \times 3,3 \mathrm{~m})$ hand-drawn and hand-built mapmodel. The map-model, collectively built by the students, disclosed two levels of 'invisible' connections, or two sets of hyperlinks: the first is composed by a set of 'invisible geographies' that appeared visible as traces on the map once UV lights were switched on (Figure 1); the second set of hyperlinks connected the symbols representing the physical geographies on the map with a few spots in the city where students translated those symbols in writings and signs at scale 1:1 (Figure 2).

As a title for this overall mapping exercise-both object and practice-we proposed that of 'Analogue City,' where the term Analogue is used both as the antonym of digital and as an explicit reference to the work 'Analogous City,' a plan of an imaginary city conceptualised by the Italian architect Aldo Rossi and made in collaboration with Eraldo Consolascio, Bruno Reichlin, and Fabio Reinhart for the Venice Biennale of Architecture of 1976 (Rossi, 1976). Rossi derived the term 'analogous' from the correspondence between Freud and Jung that defined the 'analogous' as the thinking by analogies, such as the contemplation of the 'sensitive' and 'fantastic' material of the past (Lampariello, 2017). Asserting this definition, Rossi proposed a plan of a city made out of architectural projects, or pieces of them, derived both from contemporary, imagined and, most importantly, historical architectures (Lampariello, 2019; Rodeghiero, 2016). The 'Analogous City' is a plan that connects by analogy pieces of map with pieces of reality, of imagination, and of history; a plan where architecture has been derived out of its context. In this sense, while Rossi's
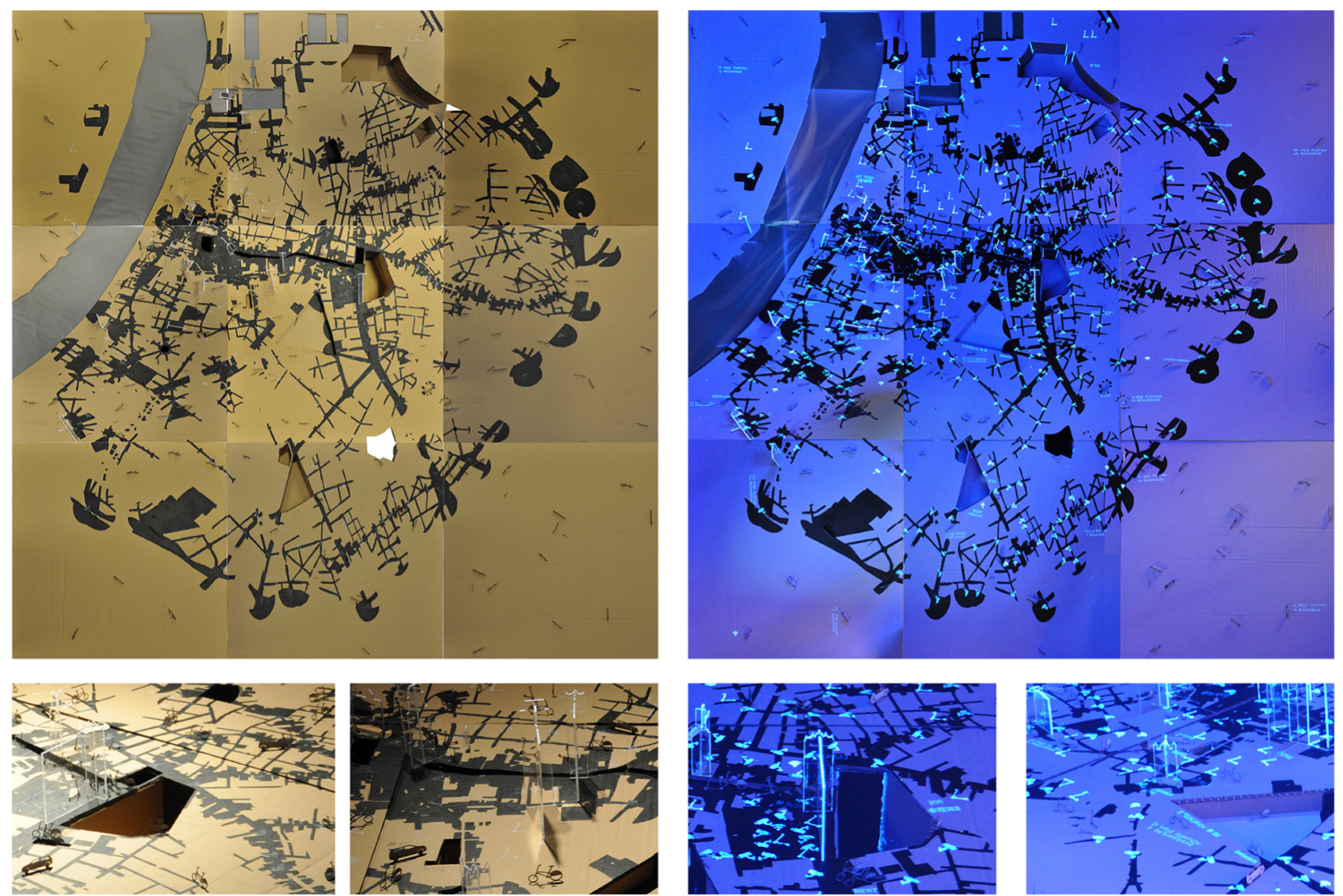

Figure 1. The two configurations of the 'Analogue City' map: under ordinary light (left) and under UV-light (right). The UV-lights were turned on upon filling out a questionnaire about the influence of digital devices on the city of Antwerp. Source: The 'Analogue City,' IDW University of Antwerp 2019 students, and the authors. 

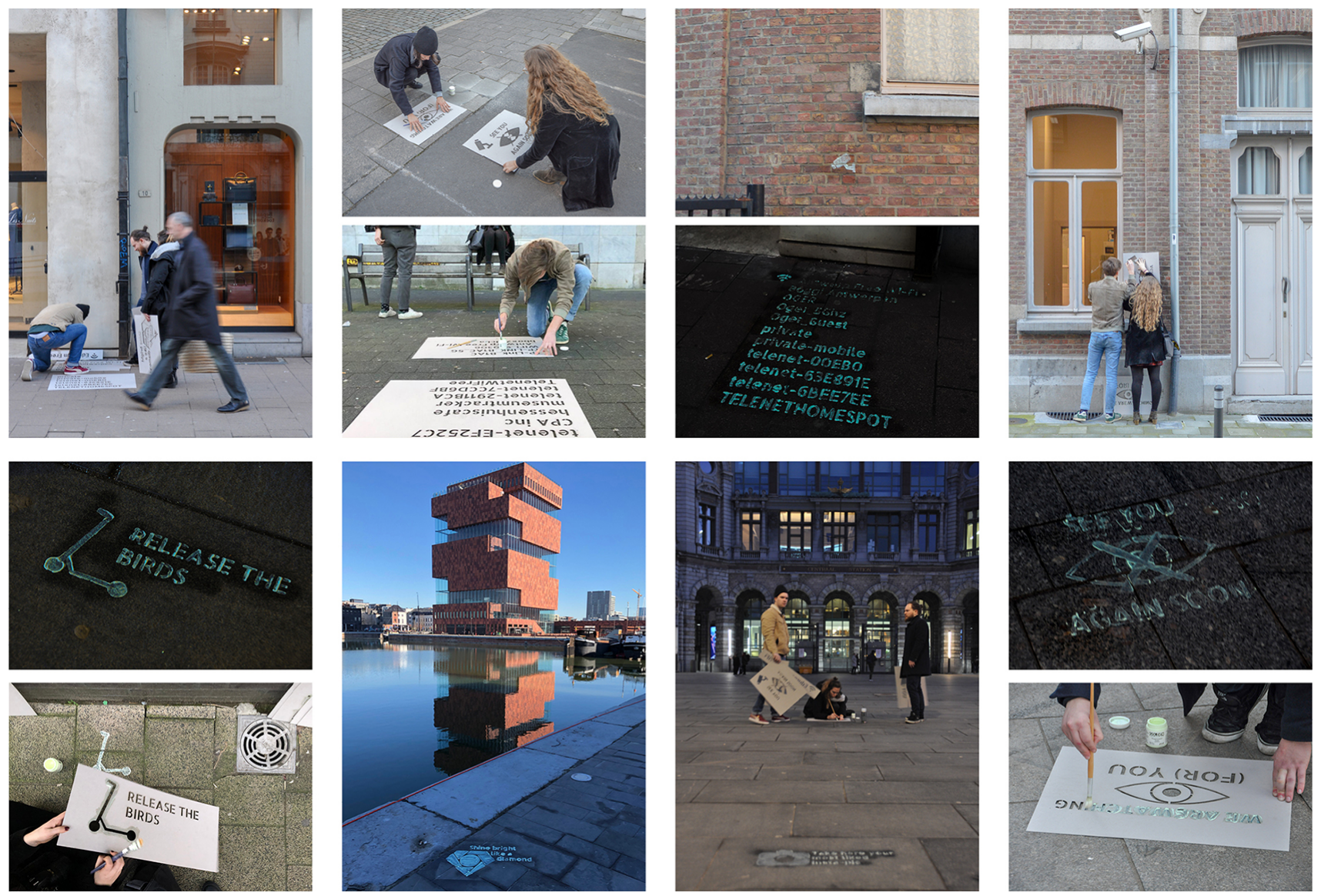

Figure 2. Process and effect of interventions in the space of the 'Analogue City' that were painted with fluorescent paint and as such became more present after sunset. The street paintings served as hyperlinks connecting the data-points of the 'Analogue City' map with their actual place. Source: The 'Analogue City,' IDW University of Antwerp 2019 students, and the authors.

interest lay more in that of a dimension of surroundings and memory, our 'Analogue City' rather looks at the present of an or any 'realtime' city. Nevertheless, we share with Rossi the materiality of his 'Analogous City': the 'Analogous City' is indeed also an unusually large object $(2 \times 2 \mathrm{~m})$, a handmade collage produced for an exhibition whose intention was that of reshaping collective imaginaries around the subject of history. In this sense, we could argue that the 'Analogue City' aims to sensitise the public while visualising a series of invisible yet existent geographies; geographies that we observed within the space of digital infrastructure, as conceived by Blum (2012) and Starosielski (2015) or explored by Nancy Couling (Couling \& Hein, 2018); geographies that ultimately are problematised by Graham and Marvin (2001) as a network that intertwines with the urban landscape, from the local level to a planetary scale (Brenner \& Schmid, 2015), where the notion of 'extended' urbanisation further translates into that of extended networks (Morata, Cavalieri, Rizzo, \& Luciani, 2020). In particular, our attention first focused on 'everyware' devices (Greenfield, 2006) such as for example wi-fi, shared mobility devices, money transfer hubs, traffic and control cameras, waste collectors, weather sensors, and water level monitors. These are devices that reveal the connection between flows of information and urban space, which represent the input and output of such information within cities and territories, and which embody the ultimate shift in-between information flows (invisible) and urban space (visible). In other words, the digital infrastructure is here conceived as suggested by Rabari and Storper (2015), as a 'deep' skin that shapes the physical urban space, as the bridge in between 'virtual' and 'physical' space, between quantifiable and unmeasurable information.

\section{From Digital Geography to Descriptive Urbanism}

The proposed method refers to recent traditions of both surveying the digital in the city (Greenfield, 2006) and of surveying the city by experiencing and walking it (De Certeau, 1984; Secchi, 1992). Within this framework of reference, the increasing role and influence of 'digital' as both a support and a subject of urban analysis can be credited as the result of a twofold trajectory. First, surveying the digital can be considered as a consequence of the geographic 'quantitative revolution' (Adams, 2001; Barnes, 2004; Harvey, 1972), par- 
tially related to the prosperous development of statistical and quantitative analysis in the field of cartography since the 19th century (Akerman \& Karrow, 2007; Chapel, 2018). Secondly, digital as a way of mapping symbolises the stabilisation of a specific 'style' of urban analysis, one based on data, figures, and quantitative analysis; on the idea of "dimensioning" and "standardising" spaces and plans (Palermo, 1992; Secchi, 1995a); on prescriptive and predictive approaches. In this sense, the emergence of critical cartography (Harley, 1989) as a reaction of this twofold trajectory also becomes pioneer in preceding a series of 'counter' cartographies that started to emerge during the 1990s. During this decade, the diffusion of mapping as both a participative, indigenous, community based, ethnographic practice (Lin, 2014) and as the output of a descriptive urbanism (Secchi, 1992) started to build a consistent body of knowledge that countered the increasing development of technology, by introducing multiple and alternative perspectives through which it critically read the notion of 'digital geographies.'

Among these perspectives, 'Descriptive Urbanism' represents a current that, while contrasting a positivist approach such as a 'quantitative' one, proposes a set of on-field tools as means for building an 'experienced' knowledge of places. The term description as a way of analysing city and territories was coined in the early 1990 s by the Italian urbanist Bernardo Secchi. For Secchi (1995b), description is a 'dense operation,' one that: (a) listens; (b) surveys; and (c) analyses people and spaces within their own environment. Description is a process that cannot disregard the direct experience of places, one which seeks the specific and the local rather than the generic, one where the differences become persistent (Secchi, 1995b). Description is then the result of an intense process of walking, field-working, interviewing, sketching, picturing, selecting, delayering, and recomposing; an extreme effort of translating the urban reality into the space of paper. Replying to a call of the same Bernardo Secchi for an international seminar whose title was 'Describing Territory' (30.03-1.04 1995, Prato, Italy), André Corboz (1995), historian of architecture and urbanism, defines description as an active, never-ending and necessarily selective operation that inevitably ends by transforming, and thus designing, the very same object of observation. In this sense, describing means both 'reading' and 'writing' the territory. A few years later, within the same line of thinking, the Italian geographer Giuseppe Dematteis (1995) defines this manifold operation as an "implicit project," a descriptive and never neutral one (Viganò, 1999). A few years later, and within the same framework of thoughts, the act of mapping-as the result of diverse operations-started to gain a certain autonomy and specificity in designating a powerful tool for design investigations (Corner, 1999). In this perspective, mapping, as both an object and a practice (Crampton, 2009) empowers a subjective process of understanding and translating reality according to both personal interpretation and to the intention of the map- maker. Following such a line of thought, the direct experience of places becomes a fundamental element of mapping processes performed by architects and urbanists.

Nevertheless, despite the 'descriptivism' period, today the maps of architects and urbanists often reflect the influence of both 'quantitative' and 'qualitative' cartography, and hence intertwine 'descriptive' with 'computing' operations. In this sense, maps diversely balance the use of qualitative and quantitative observation, of a direct and indirect experience of place. We can then argue that maps are often the results of two main traditions of analysis-that of 'describing' or 'computing': the former observing urban structures, resulting from surveying processes, sourcing from direct experience, supporting descriptive analyses, and ultimately designing spaces; the latter rather observing urban societies, resulting from computing processes, sourcing from statistical data, supporting predictive analyses, and ultimately spatialising quantities. Beside a general 'territorial turn' in architecture and urbanism during the early 1990s (Cavalieri \& Cogato Lanza, 2020), over the decades, these two mapping dimensions of describing and computing, featuring a respectively more humanistic and a more scientific approach (Travis, 2014), have cyclically returned to the vocabulary of architects and urbanists. With that respect, this work proposes to explore the space of computing with the tools of description, of a field survey; to observe, conceptualise, and categorise the digital as an experienced infrastructure. Moreover, by proposing to survey by walking, this work inevitably refers to the field of psychogeography-as both to the Situationists experience and to the work of Kevin Lynchand refers to their reconceptualising and retracing the city as a sum of 'unités d'ambience,' as different series of spaces connected by sensible, invisible, and not automated rules revealed by an intensive work of experiencing, field-working, and 'dérives' (Wood, 2010).

\section{Mapping Digital Geographies}

At the beginning of the workshop we had a clear output idea-that of a big handmade map-but we missed the collective exploration of places and the consequent elaboration and conceptualisation of the categories of spaces we wanted to represent, that is to say, the legend of our map. This legend was given shape during the workshop week and, most importantly, resulted from a continuous discussion with an interesting and interested group of master students (Simón Cebrián Saiz, Emma Claassens, Stijn Clavie, Sofie David, Ward Mertens, Yulian Peetersa, Estefania Prado Clavijo, Stef Talboom, Ot Van Eysendeyk, Ellen Van Hove, Bram Van Hoye, Dorian Van Spaendonk, Hanne Verbauwhede, Roela Waegemans). The students, despite coming from quite diverse programs (architecture, interior architecture, product development, heritage studies, urban planning), sharedtogether with us-a common understanding of 'design as a culture.' The following paragraphs illustrate the 
methodology elaborated and then applied in performing this experience: Firstly, an understanding of the context (Section 3.1), and secondly a selection of critical spaces (Section 3.2).

\subsection{Describing Antwerp: The Presence of the Digital}

The study area for this experiment was the city of Antwerp, the same city where most students lived. A space we started to observe, reconceptualise, and ultimately map from a different perspective, that of invisible flows of information. More precisely, we studied and interacted in the area between the river Scheldt and the ring road surrounding Antwerp's city centre within a square of 5 by 5 kilometres (Figure 3). Furthermore, this area, beyond representing the students' everyday habitat, contains a high concentration of digital infrastructures: The same area hosts the collaborative project 'The City of Things,' a project developed between the City of Antwerp, the Flemish Region, and IMEC, a worldleading R\&D and innovation hub in nanoelectronics and digital technologies. From 2017 to 2019, the city of Antwerp has been the test-site of their 'Smart City Living Lab,' which focused on four strategic priorities: mobility, security, sustainability and digital interaction with citizens (IMEC, 2017). For this purpose, a fine-grained network of smart sensors and wireless gateways was installed around Antwerp's buildings, streets, squares, and other city properties.

Within this specific context, the students were asked to perform a description of these spaces that had to be done with the traditional tools of descriptive analysis. A description whose main objective was that of becoming a 'performative act,' that is to say of sending a clear mes- sage to the public about such a massive presence of digital infrastructures, data production, and recording within public -and private- realm. To archieve such an objective, the fieldwork played a key role: a situated, selective, and rather slow act (Secchi, 2000) of experiencing places and interacting with their users, a process that is clearly radically opposite to the speed and the a-selectivity of data generation, registration, and accumulation.

To stimulate the students' thinking and critical reflection we set up a collective fieldwork, where we were accompanied by the artist Maarten Inghels, author of the artwork 'The Invisible Route' (2017). This artwork is a cartography that, thanks to a 'descriptive' survey on field (on June 21, 2017), reveals the only remaining north-south route in Antwerp that falls entirely outside the 'controlled' space, that is a path devoid of both public and private security-cameras. This revealing-and yet still incomplete-map of Antwerp, while showing an extensive 'security' network, became a source of inspiration for the students' work.

Moreover, during the fieldwork we walked through the St-Andries neighbourhood, gated as a 'Smart Zone,' where pedestrian and biker movements were registered and studied in order to adapt traffic lights in real time, increase the safety of crossings, and the efficiency of movements by soft mobility users. While walking, observing, discussing, and sketching, the fieldwork represented the first act of a rather collective work of revealing.

\subsection{Layering Digital Infrastructure}

In the next two days, on the basis of the information collected during the fieldwork, open discussions, and small individual researches, we-tutors and students-
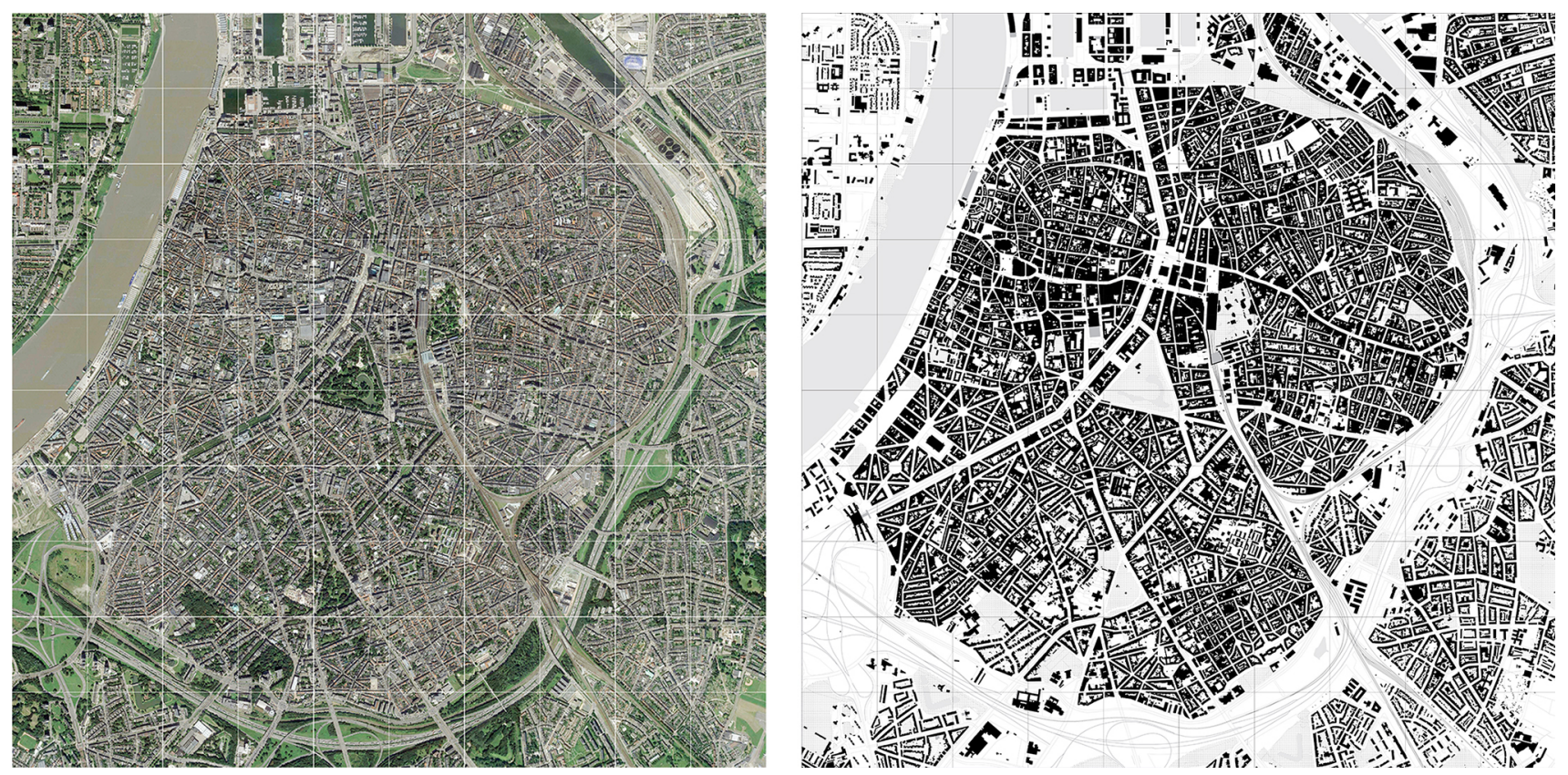

Figure 3. Area of $5 \times 5 \mathrm{~km}$ of Antwerp, city and subject of the 'Analogue City' workshop. Left: Aerial picture. Source: Google Earth. Right: Urban footprint. Source: Geopunt Vlaanderen. 
defined different digital categories to be investigated more in depth. These categories represent the base for the 'Analogue City' map. During the first discussions, several themes and ideas emerged: Some of them evolved further, others were added, and some were discarded due to being too difficult to grasp or to map within the given time frame. For example, we excluded the idea of mapping geographies generated by smartphones, not only because of the impossibility of dealing with continuously moving devices from which we could not retrieve any data, but also because our understanding of 'digital' aimed to go beyond the obvious equation 'digital' = 'smart'(phone), and reflect on the digital as part of the urban infrastructure (along with the most classical of energy, waste, water, etc.). By the third day these discussions resulted in the selection of three main layers that were to be traced, revealed, and mapped. The first layer (a) examined the spatial traces of the growing use of shared mobility; (b) the second layer considered the image of the city as perceived through social media, analysing the density of 'digital monuments'; and finally, the third layer (c), rooted in the work of Maarten Inghels, explores the spatial figure of an extensive network of security cameras.

While considering and evaluating this selection, it is important to bear in mind that this exercise was performed in five days, and that the main objective of this cartography was that of revealing 'digital geographies' rather than that of being exhaustive both in the choice of themes and the gathering of the ultimate dataset.

For the shared mobility (a), out of a plurality of options spread out in the city of Antwerp, we decided to explore a set of diversely dynamic devices, by selecting: the more 'dynamic' electric scooters, focusing on the company 'Bird'; the 'semi-dynamic' Antwerp Citybike network; and the 'semi-static' shared-car system of the company 'Cambio.' The main difference between the three observed cases is their degree of 'flexibility' of pick up and drop off points: Bird-scooters have no designated drop off points, whereas the City-bikes have fixed drop off points but they can be indiscriminately delivered in any of the different stations (semi-dynamic systems). Lastly, the Cambio-cars start from and have to be brought back to the same station (semi-fixed systems). In that respect, the Bird-scooters were mapped on two moments in time, the 14th of February 2019 at 7h00 (to capture their points of departure, also determined by the movement and user patterns) and that same day at $17 \mathrm{~h} 00$, when students leave school and universities and employees leave their work. For the City-bikes and Cambio-cars, we mapped their stations and the scale of each station as it is displayed in the map reflects the number of bikes or cars available at one of these points at a specific moment in time (14.02.2019, 17h00; Figure 4).

The second layer (b) is a layer that questions the presence of social networks within contemporary space. In this chapter, students explored the facets that were mainly linked to social media, where the evaluation of their success translated into a number of posts that used 'hashtags' and 'geotags' attributed to a specific place or building; in other words, we observed how often some places are referenced on social media. This layer attempts at portraying a renewed category of 'monuments,' the digital ones. With the word 'monuments,'

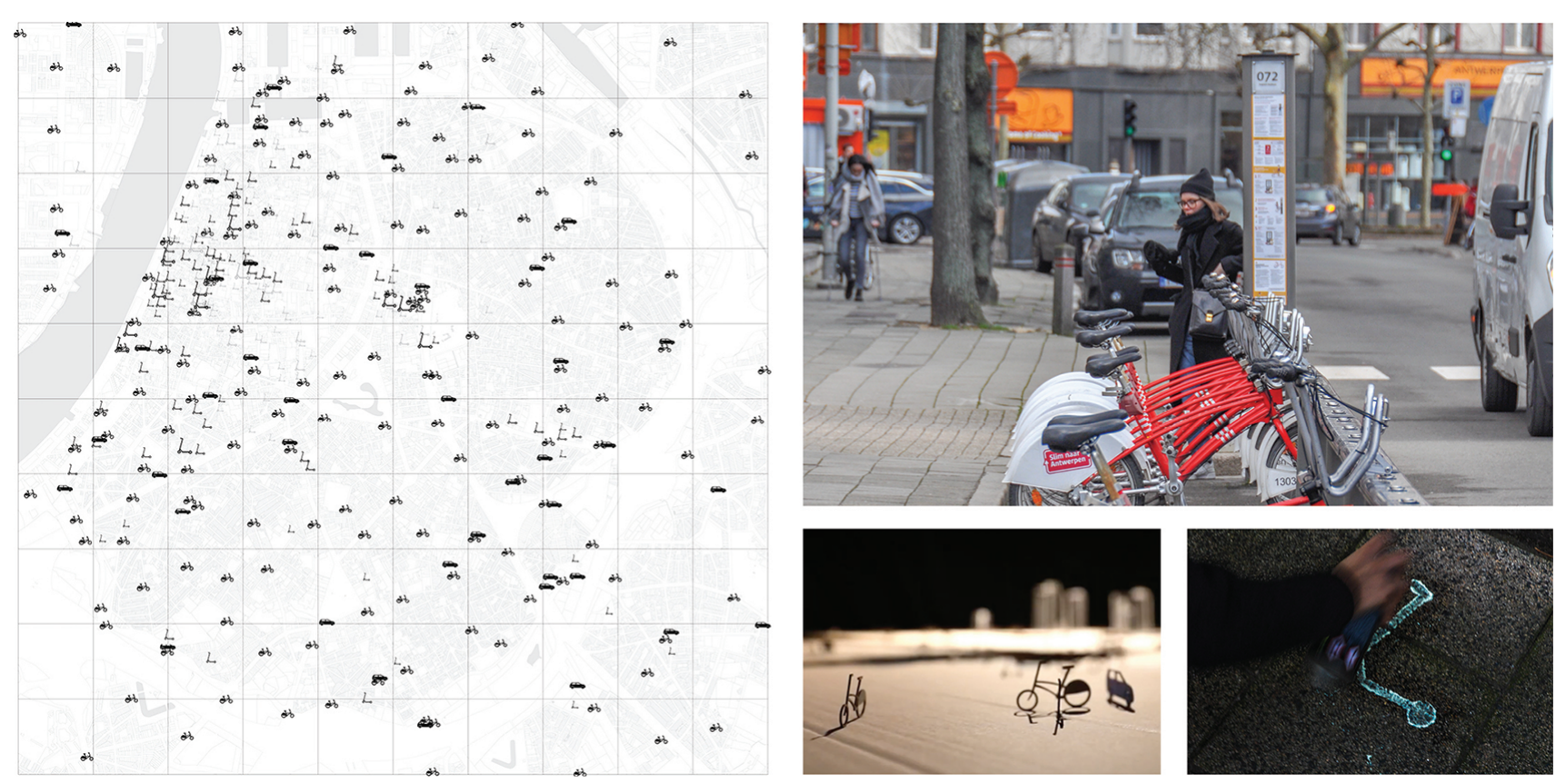

Figure 4. Shared mobility patterns. Left: Map-Traces of different shared mobility features, e-scooters, bikes, and cars in the city of Antwerp. Above right: Picture of City-bike station. Right below from left: Depiction of mobility in the 'Analogue City' map; street painting marking the data point of the map. Source: The 'Analogue City,' IDW University of Antwerp 2019 students, and the authors. 
we not only refer to protected 'heritage' but also to those buildings or spaces that become key in gathering everyday social life (Secchi \& Viganò, 2011) in the city of Antwerp. For the sake of time, we decided to adopt a deductive approach, where first the students, based on their own experience of the city, listed potential 'monuments', and then they looked up the hashtags that were used in referencing each selected monument. The amount of posts on Facebook and Instagram that had been geotagged were then counted and plotted on a bar chart. This list of places had to be represented on our map, and thus, in order to obtain a scale of value that could translate differences into an effective visual representation, the number of posts was plotted onto a logarithmic scale with a 10 base. This operation resulted in a sufficiently varied scale of values that allowed us to redraw the silhouette of 'digital monuments' where their height represented the quantity of post, rather than the physical features of the building. As for their visual rendering, each 'digital monument' was cut out of acrylic plastic and placed on the map (becoming here a three-dimensional object), thus picturing a new skyline of 'invisible appreciation.' Finally, those 'monuments' that are open spaces-rather than buildings-were represented as sunken surfaces on the map, creating a relief where the depth corresponds to the counted data (Figure 5).

Finally, the last layer (c) is inspired by the work of Inghels in 2017. Since the 1990s, surveillance cameras have become an increasingly present feature in both public and private domains of cities. Ever since this new geography triggered a continuous debate that either defended their purpose of rendering public spaces safer and reducing crime, or contested the reduction of privacy caused by being continuously watched and recorded. Framed in one sentence, we defined these (security) cameras as always and everywhere 'watching (for) you.' In this scheme, the work aimed at generating a new image of open space, a sort of inverted 'Nolli plan' where the black, that traditionally depicted private space, instead became the space of control. For the sake of simplicity and the construction of the mapped image, we did not distinguish the different types and characteristics of surveillance cameras. Instead, we represented them homogeneously covering a range-radius of about $125 \mathrm{~m}$. To provide the information for such a complex layer, the students started by transcribing the already extensive, but yet incomplete, network mapped by Inghels in 2017. Through several on site explorations, the students then verified and updated that initial 'database,' limiting their observation to within the Antwerp ring road. However, despite the resulting image being quite precise, it can be deemed to be incomplete and certainly no longer up to date (Figure 6).

\section{The 'Analogue City'}

Besides the selection of themes and their visualisation on a map, the 'Analogue City' as an act of 'performative cartography' ended up as being much more complex object, a process that produced three different spaces or levels of readings: (a) that of a hand-drawn large map, as the result of the act of surveying, conceiving, and ultimately transcribing Antwerp's digital 'skin' onto a map;

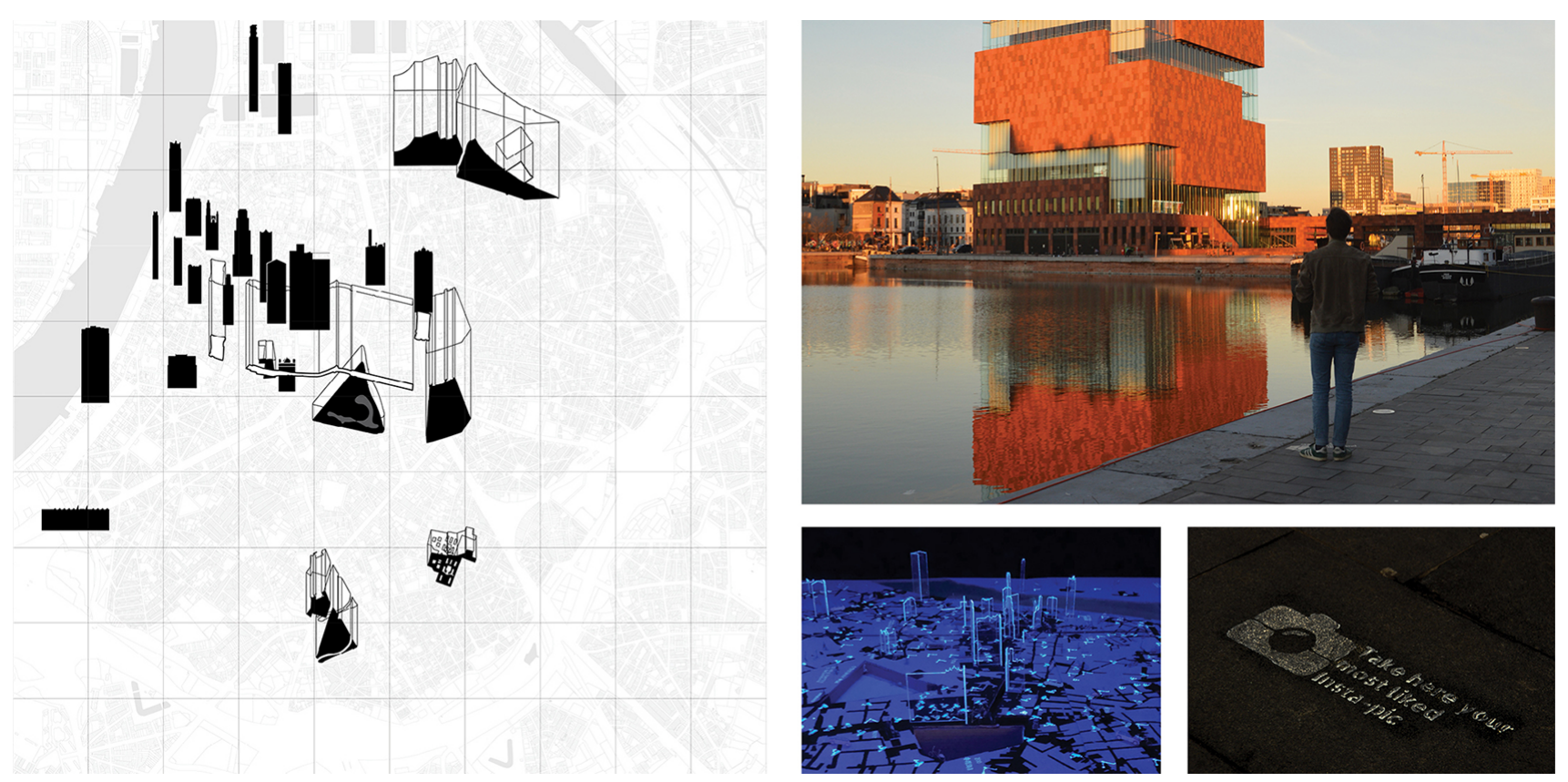

Figure 5. 'Digital monuments.' Left: Map-An image of some of Antwerp's most digitally present icons and public spaces. Above right: The MAS Museum, one of the most digitally present monuments. Below right, from left: Depiction of digital monuments in the 'Analogue City' map; street painting marking the data point of the map. Source: The 'Analogue City,' IDW University of Antwerp 2019 students, and the authors. 

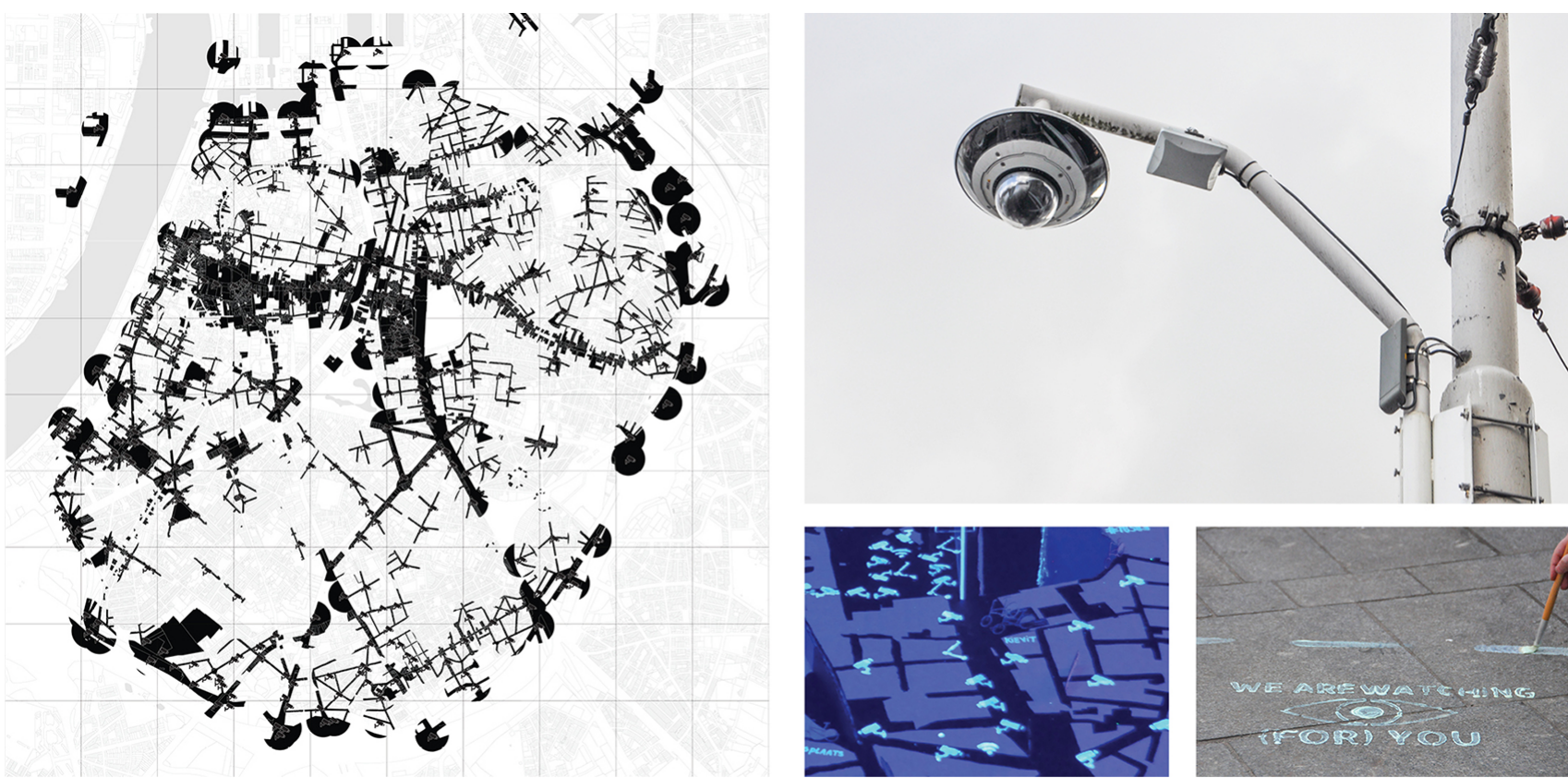

Figure 6. Surveillance. Left: Map-'Watching' (for) you (the map covers the large majority of surveillance cameras within the public domain that were detected during the workshop. There might possibly be more). Above right: Image of spaces controlled by surveillance cameras in the centre of Antwerp. Below right, from left: Depiction of cameras visible under UV-lights in the 'Analogue City' map; street painting marking the data point of the map. Source: The 'Analogue city,' IDW University of Antwerp 2019 students, and the authors.

(b) that of some punctual interventions 1:1 in space, sort of hyperlinks in between the space of the map and that of reality; and lastly (c) a scenography that ultimately turned the same map into a temporary installation.

As a map (a), the 'Analogue City' is a threedimensional object of 3,33 $\times 3,33 \mathrm{~m}$, portraying a frame of $5 \times 5 \mathrm{~km}$ of the city of Antwerp on a scale of $1: 1500$. As pointed out, the map is the result of a collective operation, one of surveying, elaborating, conceptualising, and gathering our own digital geography onto paper. The physical outcome is an intentionally large object, one able to gather people around it and to employ its own materiality to ultimately generate debate about its (in)visibility.

The second level (b) is that of reading the double links of the map: On the one hand, a family of links within the same map, a set of symbols of invisible geographies (mobility, social network, and security control) that appear and disappear thanks to the combined use of UV lamps and fluorescent ink; on the other hand, some of these places (the position of scooters, monuments, and security cameras) have been translated in physical space in the form of fluorescent signs or wording that glow in the absence of daylight. In other words, the three families of digital geographies have been translated into punctual interventions throughout the city of Antwerp, where fluorescent ink painted on the ground or on the walls of buildings had the same effect in physical space as the UV ink on the map. Mirroring the themes of the maps, we painted some disappearing positions of a Bird-scooter as indication of the shared mobility digi- tal infrastructure, we highlighted the best points to 'take your Instagram picture,' pointing out the presence of 'digital monuments,' or ultimately we traced the surveillance radius of some security cameras (Figure 2 ) in order to reveal the invisible border of spatial control. This sort of site-activation act aimed at provoking a reaction both during the process of their making, through discussion with people in the space, and in their final form, as markers of an invisible presence.

Lastly, as a three-dimensional space, as a scenography (c), the 'Analogue City' was a dark room built around the map and that contained all these materials. This third space is a temporary one, collectively built and inaugurated on the fifth and last day of the workshop and exhibited for two days. In addition to the 3,33 $\times 3,33 \mathrm{~m}$ map, inside the room we implemented a general questionnaire that raised basic questions about data production in the city. The quiz ended with a button (hand-built by the students of the Product Development Program) that covered an invisible switch that turned the regular lights off and the UV lights on for ten seconds, thus revealing the 'invisible' within the materiality of such a map. Along with the dark room, the exhibition featured other materials exhibited in the same installation rooms that described the process of making (using wording, drawings, and pictures; Figure 7).

\section{Mapping between Analogue and Analogies}

In the case of the above-described experiment, the use of cartography as both a knowledge producer and 
as a performance enabled the reading both on paper and in space of some otherwise invisible yet tangible geographies. Despite the limited time, the necessarily superficial investigation of the selected topics, and the at times inevitable incompleteness of information gathered, the overall process of mapping has anyhow fulfilled the main objective of engaging students and people with a dimension - that of the digital infrastructurethat might tend to be overlooked in people's everyday urban encounters. By collecting the data directly from the field, rather than from given datasets, the link between virtual and physical is reinforced rather than abstracted. For instance, in the mapping of the camera surveillance each point on the map not only represents a camera but is also connected with the spatial experience of that specific location. Furthermore, the long process of representing information through painting, cutting, gluing, etc. as opposed to the process of data processing, actively engages the map makers as subjects within a process of translating a sensory experience into a mapping practice and vice-versa. More in general, the 'Analogue City' as an overall operation, opens up different paths of reflection. As a performance (a), it is an action that, through its three dimensionality and sheer size, is able to address a broader public-such as the passersby and the visitors to the exhibition-and thus becomes a trigger for an everyday collective discussion (Wilson, 2019; Figure 8). In this sense, the 'Analogue City' aims to shape imaginaries around the 'geography of digital' as Rossi's 'Analogous City' aimed to shape imaginaries around the 'geography of history' (Rossi, 1966). As an image (b), the 'Analogue City' is neither a nostalgic nor a utopian one, but rather an act that aims to unfold the city not only as the result of a computational system, but rather as a cultural and manifold object (Mattern, 2017). In this sense, the term 'analogue' plays within the notions of both analogy and analogous - as the antonym of the digital-for entailing the experience of the physical space, and builds its analogies in the form of an analogous map. Lastly, as an exhibition (c), the 'Analogue City' is a temporary
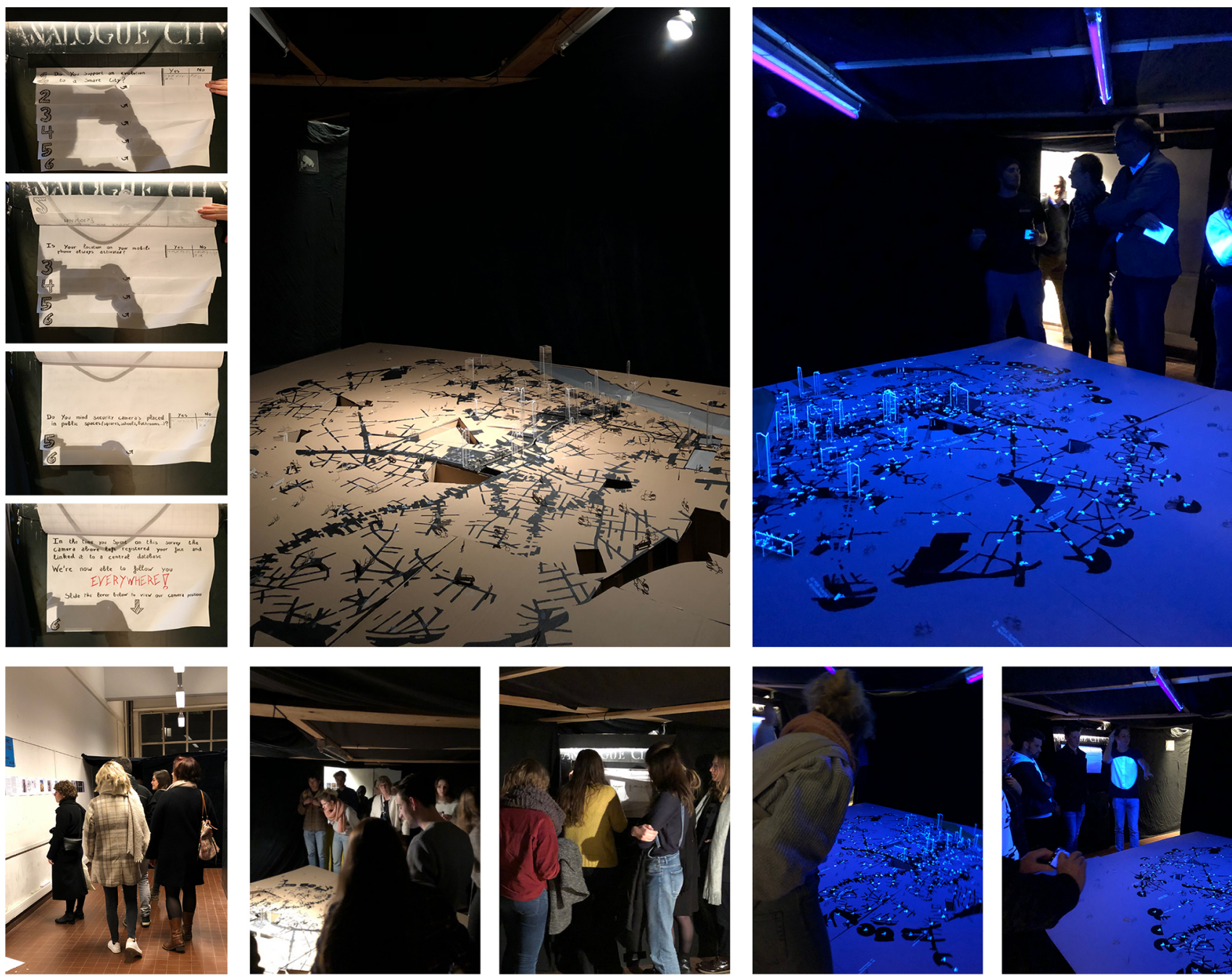

Figure 7. Exhibition at the last day of the workshop: An introduction of the explorations, leading towards a dark room that contained the 'Analogue City' map, that showed another image when the UV-lights were turned on (pictures to the right) in reaction to an 'analogue quiz.' Source: The 'Analogue City,' IDW University of Antwerp 2019 students, and the authors. 

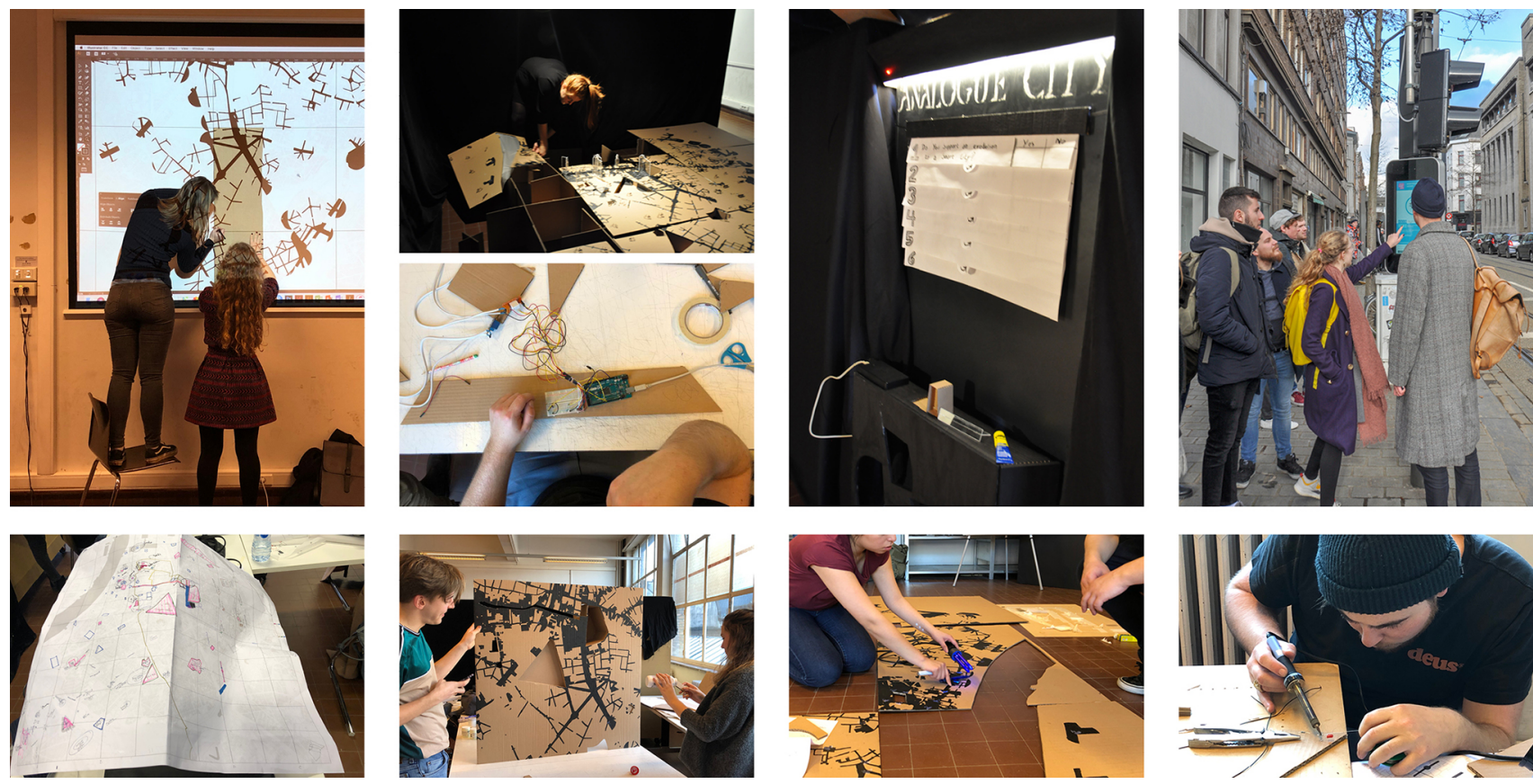

Figure 8. Process of dialogue, interdisciplinary collaborations, and creative production as an integral part of the performative cartography in the 'Analogue City' workshop at the University of Antwerp. Sources: The 'Analogue City,' IDW University of Antwerp 2019 students, and the authors.

object, one that builds strength in its provisional dimension and ultimately one that reveals analogies between the space of the paper and the physical space. Rossi's map of the 'Analogous City,' also temporarily exhibited, was a composition of architecture from the past, present and future, of both the existing and the imaginary interlacing the physical with the non-physical. By analogy, our 'Analogue City,' acts as a mapping process that collects data through a 'descriptive' analysis, hence continues on this very line of thinking by capturing that which can be difficult to quantify and combining it with conventional cartography. The core of this operation ultimately lies in the combination of two spaces-the cartographic and the physical-which is able to generate novel readings and understandings of the city itself.

\section{Acknowledgments}

We would like to thank the University of Antwerp for giving us the occasion of developing this work. Thanks to all the students (Simón Cebrián Saiz, Emma Claassens, Stijn Clavie, Sofie David, Ward Mertens, Yulian Peetersa, Estefania Prado Clavijo, Stef Talboom, Ot Van Eysendeyk, Ellen Van Hove, Bram Van Hoye, Dorian Van Spaendonk, Hanne Verbauwhede, Roela Waegemans) that contributed in conceptualising, imagining, and realising the 'Analogue City.' This article is co-written by three authors: In particular Sections 1, 2, and 5 are written by Chiara Cavalieri; Section 3 by Michaël Stas and Marcelo Rovira Torres; Section 4 by the three of us. Lastly, we would like to thank our reviewers that contributed to consistently clarifying and improving this work.

\section{Conflict of Interests}

The authors declare no conflict of interests.

\section{References}

Akerman, J. R., \& Karrow Jr., R. W. (Eds.). (2007). Maps: Finding our place in the world. London and Chicago, IL: The University of Chicago Press.

Adams, J. S. (2001). The quantitative revolution in urban geography. Urban Geography, 22(6), 530-539.

Ash, J., Kitchin, R., \& Leszczynski, A. (2018). Digital turn, digital geographies? Progress in Human Geography, 42(1), 25-43.

Barnes, T. J. (2004). Placing ideas: Genius loci, heterotopia and geography's quantitative revolution. Progress in Human Geography, 28(5), 565-595.

Blum, A. (2012). Tubes: A journey to the center of the internet. New York, NY: Harper Collins.

Brenner, N., \& Schmid, C. (2015). Towards a new epistemology of the urban? City, 19(2/3), 151-182.

Cavalieri, C., \& Cogato Lanza, E. (2020). Territories in time: Mapping palimpsest horizons. Urban Planning, 5(2), 94-98.

Chapel, E. (2018). The urbanist's eye. In S. Favaro, C. Furlan, \& A. Pagnacco (Eds.), Mapping the urban question (pp. 13-23). Rome: Officina.

Corboz, A. (1995). La descrizione tra lettura e scrittura [Description between reading and writing]. Paper presented at the 2nd International Conference on Urbanism "Describing territories," Prato, Italy.

Corner, J. (1999). The agency of mapping: Speculation, 
critique and invention. In D. Cosgrove (Ed.), Mappings (pp. 213-252). London: Reaktion Books.

Cosgrove, D. (2008). Cultural cartography: Maps and mapping in cultural geography. Annales de Géographie, 117, 159-178.

Couling, N., \& Hein, C. (2018). Blankness. FOOTPRINT, 23, 87-104.

Crampton, J. W. (2009). Cartography: Performative, participatory, political. Progress in Human Geography, 33, 840-848.

De Certeau, M. (1984). Practices of everyday life. Berkeley, CA: University of California Press.

Dematteis, G. (1995). Progetto implicito: I/ contributo della geografia umana alle scienze del territorio [Implicit project: The contribution of human geography to territorial sciences]. Milan: Franco Angeli.

Graham, S., \& Marvin, S. (2001). Splintering urbanism: Networked infrastructures, technological mobilities and the urban condition. London: Routledge.

Greenfield, A. (2006). Everyware: The dawning age of ubiquitous computing. Boston, MA: New Riders.

Harley, J. B. (1989). Deconstructing the map. Cartographica, 26(2), 1-20.

Harvey, D. (1972). Revolutionary and counter revolutionary theory in geography and the problem of ghetto formation. Antipode, 4(2), 1-13.

IMEC. (2017, January 5). IMEC collaborates with city of Antwerp and Flanders to establish Smart City Living Lab [Press release]. Retrieved from https://www. imec-int.com/en/articles/imec-collaborates-withcity-of-antwerp-and-flanders-to-establish-smartcity-living-lab

Kinsley, S. (2014). The matter of 'virtual' geographies. Progress in Human Geography, 38, 364-384.

Kitchin, R. (2014). Big data, new epistemologies and paradigm shifts. Big Data \& Society, 1(1), 1-12.

Lampariello, B. (2017). Aldo Rossi e le forme del razionalismo esaltato. Dai progetti scolastici alla "città analo$g a^{\prime \prime}$ (1950-1973) [Aldo Rossi and the forms of exalted rationalism. From school projects to the "analogous city"]. Macerata: Quodlibet.

Lampariello, B. (2019). Processi creativi del collage di Rossi: Comporre e disporre [Creative processes of Rossi's collage: Composing and disposing]. Piano $b$ : Arti e culture visive, 4(2), 16-38.

Lin, W. (2013). Situating performative neogeography: Tracing, mapping, and performing "Everyone's East Lake." Environment and Planning, 45, 37-54.

Lin, W. (2014). Counter cartographies. In P. Cloke, P. Crang, \& M. Goodwin (Eds.), Introducing human geographies (pp. 215-226). London and New York, NY: Routledge.

Mattern, S. (2017). A city is not a computer. Places Journal, 2017(February). https://doi.org/10.22269/ 170207

Merx, S. (2017). Mapping invisibility: Surveillance art and the potential of performative cartography. In T. Beyes, M. Leeker, \& I. Schipper (Eds.), Performing the digital: Performativity and performance studies in digital cultures (pp. 157-167). Bielefeld: Transcript Verlag.

Morata, B., Cavalieri, C., Rizzo, A., \& Luciani, A. (2020). Territories of extraction: Mapping palimpsests of appropriation. Urban Planning, 5(2), 132-151.

Palermo, P. C. (1992). Interpretazioni dell'analisi urbanistica [Interpretations of urban analysis]. Milan: Franco Angeli.

Rabari, C., \& Storper, M. (2015). The digital skin of cities: Urban theory and research in the age of the sensored and metered city, ubiquitous computing and big data. Cambridge Journal of Regions, Economy and Society, 8(1), 27-42.

Rodeghiero, D. (2016). The analogous city: The map. Lausanne: Archizoom EPFL.

Rossi, A. (1966). L'architettura della città [The architecture of the city]. Venice: Marsilio.

Rossi, A. (1976). La città analog: Tavole [The analogous city: The panel]. Lotus International, 1976(13), 5-10.

Secchi, B. (1992). Urbanistica descrittiva [Descriptive urbanism]. Casabella, 588, 22-23.

Secchi, B. (1995a). La stanca analisi [The bored analysis]. Urbanistica, 109, 38-41.

Secchi, B. (1995b). Dell'utilità di descrivere ciò che si vede, si sente, si tocca [On the usefulness of describing what we see, feel and touch]. Paper presented at the 2nd International Conference on Urbanism "Describing territories," Prato, Italy.

Secchi, B. (2000). Prima lezione di urbanistica [First lesson of urbanism]. Rome: Laterza.

Secchi, B., \& Viganò, P. (2011). La ville poreuse: Un projet pour le grand Paris et la métropole de l'après-Kyoto [The porous city: A project for Greater Paris and the post-Kyoto metropolis]. Geneva: Metis Presses.

Starosielski, N. (2015). The undersea network. Durham, NC: Duke University Press.

Travis, C. (2014). Transcending the cube: Translating GIScience time and space perspectives in a humanities GIS. International Journal of Geographical Information Science, 28, 1149-1164.

University of Antwerp. (2018). Edition 2019: LIMINALITY. University of Antwerp. Retrieved from https:// www.uantwerpen.be/en/projects/internationaldesign-workshops/previously/liminality--2019-

Verhoeff, N. (2012). Mobile screens: The visual regime of navigation. Amsterdam: Amsterdam University Press.

Viganò, P. (1999). La città elementare [The elementary city]. Milan: Skira.

Wilson, M. W. (2019). Mapping. In J. Ash, R. Kitchin, \& A. Leszczynski (Eds.), Digital geographies (pp. 49-59). New York, NY: Sage Publications.

Wood, D. (2010). Lynch Debord: About two psychogeographies. Cartographica: The International Journal for Geographic Information and Geovisualization, 45, 185-199. 


\section{About the Authors}

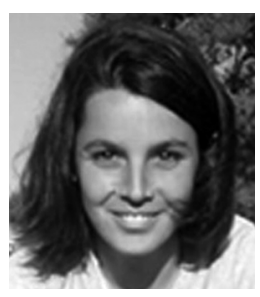

Chiara Cavalieri, Architect and with a PhD in Urbanism (IUAV, University of Venice), is Professor of Urbanism and Territorial Management at the Université Catholique de Louvain. Over the last years, she has collaborated and taught in the field of architecture and urbanism at a number of different schools (including IUAV Venice, GSD Harvard, EPFL Lausanne, ITMO St. Petersburg, and ENSAP Lille) and coordinated and directed several research activities and regional visions.
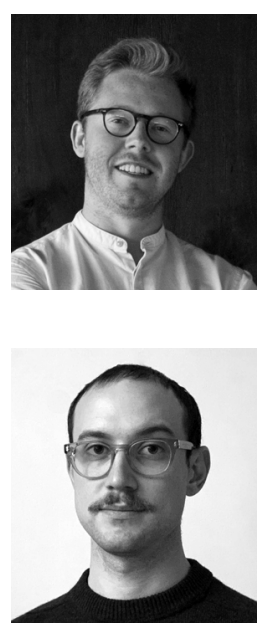

Michaël Stas is an Architect and Urbanist (KULeuven, IUAV). After graduating, he worked for 'Architecture Workroom Brussels.' Later, he became project leader at 'Studio Paola Viganò.' There, he worked on the 'Over de Ring' project in Antwerp. In 2018-2020, he coordinated the de-sealing program at 'Departement Omgeving.' Since July 2020, he is Co-Founder of Architecture and Urbanism practice 'fallow' (www.fallow.eu). In parallel, he has taught in the field of urbanism at several designschools in Europe: EPFLausanne (Fall 2017), ENSAPLille (Fall 2018-Spring 2020), and AHO in Oslo (from Fall 2020).

Marcelo Rovira Torres is a Swedish Architect and an Independent Researcher in the field of architectural theory and history. He studied Architecture at the Royal Institute of Technology, ETH-Zürich, with a Master's degree from EPF-Lausanne. In 2018, he co-founded Swedish Disgrace, an initiative that aims at highlighting forgotten Swedish architecture from the $19^{\text {th }}$ century onwards. Today, he runs his own architecture practice and regularly lectures at architecture and design schools, such as the Swedish Royal Institute of Technology, Linköping University, and Beckmans College of Design. 